\title{
Diagnostic yield and appropriate indication of upper endoscopy in Jordanian children
}

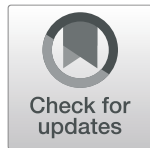

Eyad Altamimi ${ }^{1,2^{*}}$, Yousef Odeh ${ }^{1}$, Tuka Al-quraan ${ }^{1}$, Elmi Mohamed ${ }^{1}$ and Naif Rawabdeh²

\begin{abstract}
Background: Upper endoscopy is an essential tool for diagnosing pediatric gastrointestinal issues. This study aimed to assess the indications, diagnostic yields, concordance between histopathological and endoscopic findings and suitability of upper endoscopies performed at a tertiary university hospital in Jordan.

Methods: Hospital records of children who underwent upper endoscopy were retrospectively reviewed. Demographics, endoscopic details (e.g., indications, findings and any complications), and histopathological findings were collected. The relationship between endoscopic findings and histopathological abnormalities was reported.
\end{abstract}

Results: The study included 778 patients (age, $92.5 \pm 54.5$ months; 380 girls, 48.8\%). The most common age group was children younger than 60 months (273 patients, 34.3\%). The most common indication for endoscopy was abdominal pain, followed by vomiting and failure to thrive or weight loss. Normal upper endoscopy was reported in 411 patients (52.8\%). Age below 60 months, abdominal pain, dysphagia/odynophagia, and heartburn were predictive of abnormal endoscopy in multivariate analysis with $p$-value $0.000,0.048,0.001$ and 0.01 respectively. Abnormal endoscopy showed $67.3 \%$ sensitivity and $69.9 \%$ specificity to predict histopathological abnormalities. Of those performed, $13.6 \%$ endoscopies were described as inappropriate indication. The suitability of the procedure was a sensitive predictor for abnormal endoscopic and histopathological findings.

Conclusions: Abdominal pain is the most common indication for upper endoscopy in our population. It is associated with a higher chance of abnormal endoscopy. Concordance between endoscopic and histopathological findings is not high. Normal endoscopic findings shouldn`t discourage the endoscopist from obtaining tissue biopsies. Considering more biopsies may improve pathological detection rates. Compliance with established endoscopy guidelines may reduce unnecessary procedures.

Keywords: Endoscopy, Appropriate, Children, Histology, Gastritis, Abdominal pain, Children

\section{Background}

With the widespread availability of upper endoscopy, an increasing number of children are referred for endoscopic evaluation. Upper endoscopy allows for the direct examination and obtaining tissue biopsies. [1] Coupling endoscopy with histological examination increases the yield and precision of the diagnosis. In low-resource

* Correspondence: emaltamimi@just.edu.jo; eyadtamimi@gmail.com ${ }^{1}$ Pediatric Department, Faculty of Medicine, Jordan University of Science and Technology, P.O.Box. 3030 , Postal code: 22110 Irbid, Jordan

${ }_{2}^{2}$ Pediatric Department, King Abdullah University Hospital, Ar Ramtha, Jordan countries with financial hardships, this expansion places significant pressure on parents, the endoscopy team, and the health sector.

The European Society of Gastrointestinal Endoscopy (ESGE) and European Society for Pediatric Gastroenterology, Hepatology, and Nutrition (ESPGHAN) have provided evidence-based guidelines with clear indications and timing of diagnostic and therapeutic endoscopy in pediatric patients. [2] Multiple studies have examined the reliability of endoscopic indications in children against published guidelines. Lee et al. reported a high

(c) The Author(s). 2021 Open Access This article is licensed under a Creative Commons Attribution 4.0 International License, which permits use, sharing, adaptation, distribution and reproduction in any medium or format, as long as you give appropriate credit to the original author(s) and the source, provide a link to the Creative Commons licence, and indicate if changes were made. The images or other third party material in this article are included in the article's Creative Commons licence, unless indicated otherwise in a credit line to the material. If material is not included in the article's Creative Commons licence and your intended use is not permitted by statutory regulation or exceeds the permitted use, you will need to obtain permission directly from the copyright holder. To view a copy of this licence, visit http://creativecommons.org/licenses/by/4.0/ The Creative Commons Public Domain Dedication waiver (http://creativecommons.org/publicdomain/zero/1.0/) applies to the data made available in this article, unless otherwise stated in a credit line to the data. 
rate of compliance (99.7\%) with published guidelines in their cohort. This compliance predicted positive endoscopic findings, but didn't change the initial clinical diagnosis or therapeutic plan very much. [3] Jantchou et al. found that compliance with published guidelines is associated with better diagnostic efficiency.[4] On the other hand, Miele et al. examined the effect of publishing ROME criteria on endoscopic practice, they found reduction in the inappropriate procedures since publishing the criteria, on the other hand; appropriate procedures were more contributive compared to inappropriate ones. [5]

This study focused on reviewing our pediatric patients who underwent upper endoscopy in King Abdullah University Hospital (KAUH) during the study period, and it aimed at describing the patients' characteristics, endoscopic and histopathological findings, the discrepancy between normal endoscopic finding and abnormalities in histology as well as evaluating the suitability of the procedures performed.

\section{Methods}

This is a retrospective, chart-based study conducted in the Pediatric Gastroenterology Division of the Pediatrics Department at Jordan University of Science and Technology (JUST) and King Abdullah University Hospital (KAUH) (Ar Ramtha, Jordan). The study was approved by the institutional review board of the Faculty of Medicine and the Research Committee at JUST (approval no. 20,190,077).

All procedures were completed by senior pediatric gastroenterologists (EA, NR) in the pediatric endoscopy unit at KAUH. Patients underwent the procedures under light sedation with intravenous midazolam and local lidocaine spray. Heavier sedation (ketamine/fentanyl) was used on a case-specific basis.

Histopathological assessments were performed in the histopathology department at KAUH by a senior pathologist, pediatric pathologist, or gastrointestinal pathologist.

For this study, all patients who underwent upper endoscopy by a pediatric gastroenterologist at KAUH between January 2014 and January 2020 were identified. Electronic files, including clinical/inpatient files, endoscopic reports, and histopathological reports, were reviewed. For each patient, the following data were retrieved: age, sex, presenting symptoms, examination findings, laboratory test results, endoscopy abnormalities, histopathology findings, and adverse events (sedation or procedure related). The endoscopy procedure list contains both patients evaluated by the pediatric gastroenterologists and referrals.

Therapeutic endoscopy cases (retrieval of a foreign body, variceal ligation, stricture dilatation) were excluded. For patients who underwent multiple endoscopic procedures (whether as a follow-up or due to the persistence of the complaint), only the first diagnostic procedure was included. Patients who underwent endoscopy outside our facility were not considered. In addition, patients who underwent prior surgical procedures leading to expected abnormal endoscopy (for example; gastrectomy) were excluded. Procedures with insufficient data (endoscopy report or pathological report) were excluded.

We opted to use the endoscopy reports for comparison because not all patients undergoing endoscopy procedures had records of a histopathological examination.

\section{Definitions}

An endoscopy was categorized as normal when the upper endoscopy report mentioned either no abnormality or only a minor abnormality that did not contribute to the patient's illness. It was categorized as abnormal when the upper endoscopy report mentioned an

Table 1 Demographics of pediatric patients who underwent upper endoscopy from January 2014 to January $2020(N=778)$

\begin{tabular}{|c|c|c|}
\hline \multicolumn{3}{|l|}{ Age } \\
\hline Mean \pm SD (range) & \multicolumn{2}{|c|}{$\begin{array}{l}92.5 \pm 54.5 \text { months ( } 2 \text { days }-216 \text { months) } \\
\text { (2days-18 years) }\end{array}$} \\
\hline \multicolumn{3}{|l|}{ Age distribution } \\
\hline$<60$ months $(n, \%)$ & \multicolumn{2}{|l|}{$(267,34.3 \%)$} \\
\hline 60-120 months (n, \%) & \multicolumn{2}{|l|}{$(230,29.6 \%)$} \\
\hline 120-180 months (n, \%) & \multicolumn{2}{|l|}{$(264,33.9 \%)$} \\
\hline$\geq 180$ months (n, \%) & \multicolumn{2}{|l|}{$(17,2.2 \%)$} \\
\hline \multicolumn{3}{|l|}{ Sex } \\
\hline Female & \multicolumn{2}{|l|}{$380(48.8 \%)$} \\
\hline Male & \multicolumn{2}{|l|}{$398(51.2 \%)$} \\
\hline $\begin{array}{l}\text { Primary indication for upper } \\
\text { endoscopy }{ }^{{ }^{2}}\end{array}$ & N & $\%$ \\
\hline Abdominal pain/dyspepsia & 359 & 45.1 \\
\hline Vomiting & 164 & 21.1 \\
\hline Failure to thrive/weight loss & 80 & 10.3 \\
\hline Chronic diarrhea & 66 & 8.5 \\
\hline R/O celiac disease & 53 & 6.8 \\
\hline Anemia & 49 & 6.3 \\
\hline Abdominal distention & 37 & 4.8 \\
\hline Dysphagia/odynophagia & 42 & 5.4 \\
\hline Chemical ingestion & 31 & 4.0 \\
\hline Chronic constipation & 10 & 1.3 \\
\hline Heartburn & 11 & 1.4 \\
\hline Allergies & 6 & 0.8 \\
\hline Poor appetite & 5 & 0.6 \\
\hline Other & 21 & 2.9 \\
\hline
\end{tabular}

${ }^{a}$ Some patients may have more than one indication 
abnormality in any of the areas examined. Histopathology was classified as negative when a histopathological report described no abnormalities or only a mild nonspecific abnormality and positive when the report described abnormal findings.

Indication for the procedure was described as appropriate when compliant with the 2016 Pediatric Gastroenterology Endoscopy Guidelines by the ESGE and ESPGHAN, whereas inappropriate indication described noncompliance.[2].

\section{Statistical Analysis:}

Data were analyzed using IBM SPSS Statistics20.0 software (IBM Co., Armonk, NY, USA). Descriptive data were reported as percentages of the total for categorical data, as means \pm standard deviation (SD). T-test, $\mathrm{x}^{2}$ and fisher exact test were used as appropriate to compare categories, p-value of $<0.05$ considered significant. Variables identified to be significant in the univariate analysis were used as predictors of the probability of abnormal EGD findings or abnormal histopathology in the multivariate analysis.

\section{Results}

During the study period, 1,072 upper endoscopy procedures (as some patients had more than one procedures) were identified. After 313 were excluded according to the predetermined criteria (212 therapeutic/potentially therapeutic endoscopy, 23 previous upper gastrointestinal surgeries and 40 due to insufficient data), 787 patients were included in the study (average age $\pm \mathrm{SD}, \quad 92.5 \pm 54.5$ months; 380 girls, $48.8 \%)$. As shown in Table 1 , the most common age group was children younger than 60 months (267 patients, 34.23\%).

The most common indication for upper endoscopy in our cohort was abdominal pain $(n=359 ; 45.1 \%)$,

Table 2 Comparison between patients with normal and abnormal endoscopy findings regarding patients characteristics and procedures' indication(s)

\begin{tabular}{|c|c|c|c|}
\hline Feature & $\begin{array}{l}\text { Normal endoscopy findings } \\
(n=411) \\
52.8 \%\end{array}$ & $\begin{array}{l}\text { Abnormal endoscopy findings } \\
(n=367) \\
47.2 \%\end{array}$ & $p$-value \\
\hline Age (average $\pm \mathrm{SD}$ ) & $78.1 \pm 51.6$ & $107.7 \pm 53.6$ & 0.000 \\
\hline$<60$ months $\dagger$ & $177(42.4 \%)$ & $90(23.7 \%)$ & 0.000 \\
\hline $60-120$ & $133(31.9 \%)$ & $104(27.4 \%)$ & 0.165 \\
\hline $120-180$ & $92(22.1 \%)$ & $158(41.6 \%)$ & 0.000 \\
\hline$\geq 180$ & $15(3.6 \%)$ & $16(4.2 \%)$ & 0.662 \\
\hline Female & 206 (49.4\%) & $183(47.4 \%)$ & 0.554 \\
\hline Single indication & $331(79.4 \%)$ & $289(76.1 \%)$ & 0.263 \\
\hline Two indications & $76(18.2 \%)$ & $80(21.1 \%)$ & 0.303 \\
\hline Three indications & $10(2.4 \%)$ & $11(2.9 \%)$ & 0.660 \\
\hline Abnormal histopathology ${ }^{a}$ & $158(28.3 \%)$ & 309 (49.7\%) & 0.001 \\
\hline Abdominal pain/dyspepsia $†$ & $158(38.6)$ & $210(55.3)$ & 0.000 \\
\hline Vomiting & $85(20.4)$ & $74(19.5)$ & 0.715 \\
\hline Failure to thrive/weight loss & $51(12.2)$ & $24(6.3)$ & 0.005 \\
\hline Chronic diarrhea & $42(10.1)$ & $19(5.0)$ & 0.007 \\
\hline R/O celiac disease & $33(7.9)$ & $19(5.0)$ & 0.098 \\
\hline Anemia & $27(6.5)$ & $22(5.8)$ & 0.682 \\
\hline Abdominal distention & $25(6.0)$ & $12(3.2)$ & 0.062 \\
\hline Dysphagia/odynophagia† & $11(2.6)$ & $30(7.9)$ & 0.001 \\
\hline Chemical ingestion & $15(3.6)$ & $15(3.9)$ & 0.827 \\
\hline Chronic constipation & $4(1.0)$ & $6(1.6)$ & 0.453 \\
\hline Heartburn $\dagger$ & $1(0.2)$ & $10(2.6)$ & 0.003 \\
\hline Allergies & $6(1.4)$ & $1(0.3)$ & 0.225 \\
\hline Poor appetite & $3(0.7)$ & $1(0.3)$ & 0.428 \\
\hline Other & $10(2.4)$ & $11(2.9)$ & 0.661 \\
\hline
\end{tabular}

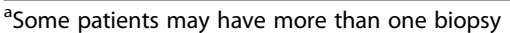


followed by vomiting $(n=164 ; 21.1 \%)$ and failure to thrive or weight loss $(n=80 ; 910.3 \%)$ (Table 1$)$.

Normal upper endoscopy was reported in 411 (52.8\%) patients. Children with normal endoscopy were significantly younger $(p=0.001)$. Neither sex nor the number of identified indications for endoscopy showed any statistical difference between the normal and abnormal upper endoscopy groups. (Table 2).

Comparing the endoscopic indications between the normal endoscopy and abnormal endoscopy groups, failure to thrive or weight loss and chronic diarrhea were significantly associated with normal endoscopy ( $p=$ 0.005 and 0.007 , respectively). By contrast, abdominal pain, dysphagia/odynophagia, and heartburn were significantly associated with abnormal endoscopy ( $p=$ 0.001, 0.001, and 0.003, respectively) (Table 2).

Abnormal histological findings were seen in 467 (39.6\%) of the examined tissue biopsies. The stomach was the most common site of reported endoscopic abnormalities $(267,32.4 \%)$ and the highest yielding site of histopathological biopsies (267/421, 63.4\%), followed by the esophageal and duodenal sites, respectively (Table 3 ). Abdominal pain, vomiting, dysphagia, and heartburn were associated with abnormal histological findings, ( $p=$ $0.0001,0.001,0.044$ and 0.020 respectively (Table 4 ). Abnormal endoscopic findings were associated with higher rates of abnormal histology with a positive predictive value of $76.8 \%$.tive (Table 5 ).

Of the 410 who had normal endoscopic findings, abnormal histological findings were reported in 133
(32.2\%). This has resulted in a change in therapeutic plan in 56 cases. H.pylori gastritis was the most common finding followed by celiac disease and reflux esophagitis. (Table 6)

According to the ESGE/ESPGHAN guidelines, 108 (13.9\%) of the procedures were considered unsuitable. Appropriate indication was a sensitive indicator for abnormal endoscopic and histopathological abnormalities (85.2\% and $90.1 \%$ respectively), but not specific $(13.1 \%$ and $23.2 \%$ respectively) (Table 7 ). Serious side effects were not reported in any of the patients.

\section{Discussion}

Pediatric endoscopy is a safe and effective diagnostic tool for children with symptomatic upper gastrointestinal lesions. Although the utility of upper endoscopy in children is on the rise, data on patients from the Middle East are scarce. This study describes the indications as well as the endoscopic and histopathological yields of upper endoscopy in patients treated at our center in Jordan. In addition, this study assesses the appropriate indication of upper endoscopic procedures according to published guidelines. [2]

Abdominal pain is one of the most common complaints of patients who present to a pediatric gastroenterology clinic. A significant portion of these children undergo upper endoscopy. In our cohort, abdominal pain is the most common indication for upper endoscopy. Sheiko et al. reported that more than one-third of children underwent endoscopy at their facility due to abdominal and epigastric pain.[5] In addition, abdominal

Table 3 Comparison of endoscopic and histopathological findings by organ

\begin{tabular}{|c|c|c|c|c|}
\hline & Endoscopic findings & Rate $^{a}$ & Histopathological findings & Rate $^{a}$ \\
\hline Esophagus & $\begin{array}{l}\text { - Erythema } \\
\text { - Ulcers } \\
\text { - Strictures } \\
\text { - Exudates } \\
\text { - Furrows, whitish plaques } \\
\text { - Circular rings }\end{array}$ & $\begin{array}{l}117 / 787 \\
(15 \%)\end{array}$ & $\begin{array}{l}\text { - Reflux esophagitis } \\
\text { - Eosinophilic esophagitis } \\
\text { - Infectious esophagitis } \\
\text { - Nonspecific inflammation }\end{array}$ & $\begin{array}{l}100 / 214 \\
(46.7 \%)\end{array}$ \\
\hline Stomach & $\begin{array}{l}\text { - Hyperemia } \\
\text { - Ulcers } \\
\text { - Nodularity } \\
\text { - Erosions } \\
\text { - Hemorrhagic spots } \\
\text { - Abnormal folds } \\
\text { - Trichobezoar }\end{array}$ & $\begin{array}{l}258 / 787 \\
(33.2 \%)\end{array}$ & $\begin{array}{l}\text { - Mild-moderate nonspecific inflammation } \\
\text { - H. pylori-related gastritis } \\
\text { - Menetrier disease } \\
\text { - Eosinophilic gastropathy }\end{array}$ & $\begin{array}{l}267 / 421 \\
(63.4 \%)\end{array}$ \\
\hline Duodenum & $\begin{array}{l}\text { - Hyperemia } \\
\text { - Erosions } \\
\text { - Ulcers } \\
\text { - Scalloping and ridging } \\
\text { - Snowflake appearance } \\
\text { - Flattened villi }\end{array}$ & $\begin{array}{l}115 / 787 \\
(14.8 \%)\end{array}$ & $\begin{array}{l}\text { - Moderate to severe inflammation } \\
\text { - Villous atrophy } \\
\text { - Giardia } \\
\text { - Lymphangiectasia }\end{array}$ & $\begin{array}{l}100 / 545 \\
(18.3 \%)\end{array}$ \\
\hline
\end{tabular}

${ }^{\text {a }}$ Rate of abnormal finding out of total reports (endoscopic or histopathologic if present) 
Table 4 Comparison of normal and abnormal histological findings by indication

\begin{tabular}{llll}
\hline Indication (n) & Normal histopathological findings & Abnormal histopathological findings & $\boldsymbol{p}$-value \\
\hline Abdominal pain/ dyspepsia (347) & $108(31.1 \%)$ & $239(68.9 \%)$ & 0.0001 \\
Vomiting (118) & $36(30.5 \%)$ & $82(69.5 \%)$ & 0.001 \\
Failure to thrive/weight loss (75) & $35(46.7 \%)$ & $40(53.3 \%)$ & 0.569 \\
Chronic diarrhea (60) & $36(60 \%)$ & $24(40 \%)$ & 0.119 \\
R/O celiac disease (51) & $24(47 \%)$ & $27(53 \%)$ & 0.669 \\
Anemia (49) & $19(38.8 \%)$ & $30(61.2 \%)$ & 0.114 \\
Abdominal distention (37) & $19(51.4 \%)$ & $18(48.6 \%)$ & 0.856 \\
Dysphagia/odynophagia (31) & $10(32.2 \%)$ & $21(67.8 \%)$ & 0.044 \\
Chemical ingestion (1) & $1(100 \%)$ & 0 & --- \\
Chronic constipation (8) & $4(50 \%)$ & $4(50 \%)$ & 1.00 \\
Heartburn (11) & $2(18.2 \%)$ & $9(81.8)$ & 0.020 \\
Allergies (6) & $4(66.7 \%)$ & $2(33.3 \%$ & 0.416 \\
Poor appetite (4) & $3(75 \%)$ & $1(25 \%)$ & 0.332 \\
\hline
\end{tabular}

pain is the most common indication for upper endoscopy in UK, Columbian, and US cohorts [6-8].

A previous study from northern Jordan by Rawashdeh et al. published in 1996 reported that small intestinal biopsies surpassed abdominal pain as an indication for upper endoscopy. [9] We believe the difference between our current report and what was reported by Rawashdeh et al. represents the current indication in Jordan. In addition, this may reflect the effect of the development of very sensitive and specific serological markers for celiac disease, which can improve the determination of patients who are in need of intestinal biopsies.

Endoscopic examination provides a specific morphological description of upper intestinal pathologies. Sheiko et al. [5] found 37\% abnormal endoscopic findings in their cohort, with the esophagus as the most prevalent organ. Meanwhile, Lyon et al. [8] reported overall endoscopic abnormalities at $54.5 \%$. In our cohort, less than half of the patients have abnormal endoscopy findings. Both Sheiko [5] and Lyon [8] reported an increased chance of abnormal endoscopy as the patient ages. In our population, bimodal trend was observed; children younger than 60 months and those older than 120 months were associated with a higher chance of having abnormal endoscopic findings. In our cohort the accuracy of abnormal endoscopy in detecting abnormal histopathology was around 67\%. This might reflect targeted lesion biopsies taken.

Indications for endoscopy influenced the chance of having abnormal endoscopic findings. Consistent with previous reports $[5,8]$, abdominal pain, dysphagia and heart burn were predictive of abnormal endoscopy in multivariate analysis. In addition, we found no association between sexes or the number of indications with abnormal endoscopic findings, which is in agreement with previous reports $[5,8]$.

In our cohort, abdominal pain is associated with a higher chance of abnormal endoscopic findings. The diagnostic yield of upper endoscopy in abdominal pain is highly affected by patient selection. A previous study from Iran reported that $84 \%$ of patients with recurrent abdominal pain had abnormal endoscopic findings, whereas another study from Kuwait reported 68\% [10]. In a study by Alabdrazak et al., abdominal pain was the

Table 5 Diagnostic yield of endoscopic procedures ${ }^{a}$

\begin{tabular}{lll}
\hline & Abnormal histopathology (n) & Normal histopathology (n) \\
\hline Abnormal endoscopy & 272 & 193 \\
Normal endoscopy & 133 \\
Sensitivity $(\%, 95 \% \mathrm{Cl})$ & $67.3 \%(62.43-71.81 \%)$ \\
Specificity $\%, 95 \% \mathrm{Cl})$ & $69.9 \%(64.02-75.25 \%)$ \\
Positive Predictive Value $\%$ & $76.8 \%$ \\
Negative predictive value $\%$ & $59.0 \%(55.08-62.82 \%)$ \\
\hline
\end{tabular}

${ }^{\mathrm{a} B i o p s i e s}$ were not taken in 122 procedures 
Table 6 Characteristics of patients with abnormal histopathological examination while normal endoscopy ( $N=$ 133)

\begin{tabular}{|c|c|c|c|}
\hline \multicolumn{4}{|l|}{ Age } \\
\hline Mean \pm SD (range) & \multicolumn{3}{|c|}{$\begin{array}{l}89.25 \pm 50.82 \text { months ( } 5-192 \text { months) }(5 \\
\text { mo. }-16 \text { yrs })\end{array}$} \\
\hline \multicolumn{4}{|l|}{ Age distribution } \\
\hline$<60$ months $(n, \%) *$ & \multicolumn{3}{|c|}{$(43,32.6 \%)$} \\
\hline $60-120$ months $(n, \%)$ & \multicolumn{3}{|c|}{$(50,37.6 \%)$} \\
\hline 120-180 months (n, \%) & \multicolumn{3}{|c|}{$(36,27.3 \%)$} \\
\hline$\geq 180$ months (n, \%) & \multicolumn{3}{|l|}{$(4,3.0 \%)$} \\
\hline \multicolumn{4}{|l|}{ Sex } \\
\hline Female & \multicolumn{3}{|c|}{$64(48.5 \%)$} \\
\hline Male & \multicolumn{3}{|c|}{$68(51.5 \%)$} \\
\hline \multicolumn{3}{|c|}{ Primary indication for upper endoscopyt $\mathrm{N}$} & $\%$ \\
\hline \multicolumn{2}{|l|}{ Abdominal pain/dyspepsia * } & 68 & 34.8 \\
\hline \multicolumn{2}{|l|}{ Vomiting } & 30 & 22.7 \\
\hline \multicolumn{2}{|l|}{ Failure to thrive/weight loss } & 11 & 8.3 \\
\hline \multicolumn{2}{|l|}{ Chronic diarrhea } & 10 & 7.6 \\
\hline \multicolumn{2}{|l|}{ R/O celiac disease } & 14 & 10.6 \\
\hline \multicolumn{2}{|l|}{ Anemia } & 9 & 6.8 \\
\hline \multicolumn{2}{|l|}{ Abdominal distention } & 6 & 4.5 \\
\hline \multicolumn{2}{|l|}{ Dysphagia/odynophagia } & 3 & 2.3 \\
\hline \multicolumn{2}{|l|}{ Short stature } & 4 & 3.0 \\
\hline \multicolumn{2}{|l|}{ Recurrent ulcers } & 3 & 2.3 \\
\hline \multicolumn{2}{|l|}{ Others } & 5 & 3.8 \\
\hline \multicolumn{4}{|c|}{ Site of Histopathological abnormalities } \\
\hline \multicolumn{2}{|l|}{ Esophagus } & 25 & \\
\hline \multicolumn{2}{|l|}{ Stomach } & 71 & \\
\hline \multicolumn{2}{|l|}{ Duodenum } & 49 & \\
\hline \multicolumn{4}{|c|}{$\begin{array}{l}\text { Most Common Abnormality in each } \\
\text { organ }\end{array}$} \\
\hline \multicolumn{4}{|c|}{ Esophagus : Reflux esophagitis } \\
\hline \multicolumn{4}{|l|}{ Stomach : H. pylori gastritis } \\
\hline \multicolumn{4}{|l|}{ Duodenum: Celiac disease } \\
\hline The results that affected the & nanageme & nt $(\mathrm{N}=56,42.4 \%)$ & \\
\hline Eosinophilic esophagitis (2) & & & \\
\hline H.pylori gastritis (37) & & & \\
\hline Celiac disease (17) & & & \\
\hline
\end{tabular}

*Positive predictors in multivariate analysis with $p$-value $<0.05$ tSome patients might have more than one indication

most common referral symptom and the best predictor of positive upper endoscopy, reaching an accuracy level of $79.9 \% .[11]$.

Wang et al. reported a $28 \%$ rate of abnormal histological findings in children with newly presenting gastrointestinal symptoms, which is consistent with other reports from the developed world. $[5,6,12]$. However,
Lyon found an overall histological abnormalities rate at $59.1 \%$ and that gastric pathologies are the most common. In our study, almost $40 \%$ of our patients have an abnormal histopathological finding, with the stomach as the most commonly affected organ.

Diagnostic concordance between endoscopic and histological findings may not be highly reliable. [13] In our study, abnormal endoscopy has a sensitivity of $67 \%$ in predicting abnormal histology. However, the endoscopic indication may affect histological findings. In our study, abdominal pain, vomiting, dysphagia, and heartburn are associated with abnormal histological findings. These findings are in agreement with Sheiko et al. [5].

The utility of endoscopic biopsies in otherwise normal endoscopic exam has not been well studied A previous study from Canadian Adult Endoscopy Unit evaluated utility of endoscopic biopsies in adult patients with normal upper endoscopy. The authors concluded that the yield is highly affected by the site of the biopsies. The added expenses mandate high selectivity to augment the yield [14]. Due to the different study population the reported predictors of abnormal histology in this study can't be extrapolated into pediatric population.

In our study; the biopsy yield was affected by the biopsy site. The stomach represented the most common site followed by the duodenum and the esophagus. Reflux esophagitis, H.pylori gastritis and celiac disease where the most common diagnoses. In multivariate analysis of features that could predict abnormal histopathology in our children with normal endoscopic exam; younger age group and abdominal pain were positive predictors. The small size of the group and the absence of cost-effectiveness evaluation limit generalization of our results and warrant further evaluation of such group.

The classification of suitability of endoscopic procedures would help practitioners identify which patients should undergo endoscopic evaluation. In our situation, financial resources are limited and the small endoscopy team can become overwhelmed with referrals. Jantchou et al. [4] found that $13.9 \%$ of the upper endoscopies performed at their unit were inappropriate according to Paediatric Hepatology, Gastroenterology, and Nutrition Group (GFHGNP) recommendations. Inappropriate procedures were associated with a less likelihood of detecting gastrointestinal abnormalities.[4] Meanwhile, Miele et al. found that almost one-fourth of performed endoscopic procedures were inappropriate.[15] In our cohort, compared to the 2016 ESGE/ESPGHAN published guidelines [2], only $13.6 \%$ of performed procedures have been found to be inappropriate. In our cohort, appropriate indication shows good sensitivity for predicting endoscopic and histopathological abnormalities but poor specificity. 
Table 7 Appropriate indication of endoscopic procedures as a predictor of abnormal endoscopic or pathological findings

\begin{tabular}{|c|c|c|}
\hline & Abnormal endoscopic findings ( $n$ ) & Normal endoscopic findings (n) \\
\hline Appropriate indication & 3.17 & 351 \\
\hline Inappropriate indication & 55 & 53 \\
\hline Sensitivity\% (95\% Cl) & $85.2(81.2-82.6 \%)$ & \\
\hline Specificity \% (95\% Cl) & $13.1(9.9-16.7 \%)$ & \\
\hline Positive predictive value & $47.8 \%$ & \\
\hline Negative predictive value & $47.1 \%$ & \\
\hline Appropriate indication & 391 & 183 \\
\hline Inappropriate indication & 43 & 56 \\
\hline Sensitivity \% (95\% Cl) & $90.1 \%(86.9-92.7 \%)$ & \\
\hline Specificity \% (95\% Cl) & $23.4 \%(18.2-29.3 \%)$ & \\
\hline Positive predictive value & $68.1 \%$ & \\
\hline Negative predictive value & $56.6 \%$ & \\
\hline
\end{tabular}

Further studies addressing the effect of upper endoscopy results on the patient management and reporting milder post-procedure complications are needed to improve the diagnostic yield and the procedure outcome. Evaluating patients referred for endoscopy at the pediatric gastroenterology clinic prior to endoscopy enlisting might decrease unnecessary procedures and costs.

Our study provides valuable data on the epidemiology, endoscopic, and pathological findings of upper endoscopy and the correlation between endoscopic and histological findings. However, the study has some weaknesses. First, this study uses a retrospective design. Second, endoscopic description is sometimes subjective and depends on the endoscopist, which may lead to the misclassification of the findings. Third, this study did not collect data about any pre-endoscopic treatments, which could have led to discordance between endoscopic and histopathological findings. Fourth, the inconsistent number and sites of endoscopic biopsies, which cannot be fully explained due to the retrospective nature of the study, limit the generalization of these study results. And lastly, this study didn 't quantify the effect of the procedure on the patients' management plan. Even normal endoscopy provides significant input by refuting a diagnosis or modifies treatment.

\section{Conclusions}

Pediatric upper endoscopy is a valuable diagnostic tool. Older children are associated with a higher chance of abnormal endoscopic findings. Abdominal pain is the most common indication for upper endoscopy and is associated with a higher chance of abnormal endoscopy. Concordance between endoscopic and histopathological findings is not high, so routine biopsies need to be considered. Compliance with the published guidelines could improve pathology detection rates and reduce unnecessary referrals.
Further studies on the effect of the endoscopy results on the management decisions are needed.

\section{Abbreviations}

KAUH: King Abdullah University Hospital; JUST: Jordan University of Science and Technology; ESGE: European Society of Gastrointestinal Endoscopy; ESPG HAN: European Society for Pediatric Gastroenterology, Hepatology, and Nutrition

\section{Acknowledgements}

The authors want to thank the staff of the endoscopy unit for being so helpful and professional.

\section{Authors' contributions}

Conceptualization and design: EA. Data Curation: YO, TA, EM. Data analysis: $E A, Y O, N R$. Writing the first draft: EA. Reviewing the draft: EA, NR. All authors have read and approved the manuscript.

\section{Funding}

The study received no funding.

\section{Availability of data and materials}

The datasets generated and/or analysed during the current study are not publicly available due to the regulations of the IRB but are available from the corresponding author on reasonable request.

\section{Ethics approval and consent to participate}

The study was approved by the institutional review board of the Faculty of Medicine and the Research Committee at JUST (approval no.

20190077).Consent for participation was deemed unnecessary by the IRB committee at the Faculty of Medicine at Jordan University of Science and Technology.

\section{Consent for publication}

Not applicable.

\section{Competing interests}

The authors declare they have no competing interest related to this article. Received: 7 May 2020 Accepted: 14 December 2020

Published online: 05 January 2021

\section{References}

1. Sivak MV. Gastrointestinal endoscopy: past and future. Gut. 2006;55(8):1061-4.

2. Tringali A, Thomson M, Dumonceau JM, Tavareset M, Tabbers MM, Furlano $\mathrm{R}$, et al. Pediatric gastrointestinal endoscopy: European Society of Gastrointestinal Endoscopy (ESGE) and European Society for Paediatric Gastroenterology Hepatology and Nutrition (ESPGHAN) Guideline Executive summary. Endoscopy. 2017:49(1):83-91. 
3. Lee WS, Zainuddin H, Boey CC, Chai PF. Appropriateness, endoscopic findings and contributive yield of pediatric gastrointestinal endoscopy. World J Gastroenterol. 2013;19(47):9077-83.

4. Jantchou P, Schirrer J, Bocquet A. Appropriateness of upper gastrointestinal endoscopy in children: a retrospective study. J Pediatr Gastroenterol Nutr. 2007:44(4):440-5.

5. Sheiko MA, Feinstein JA, Capocelli KE, Kramer RE. Diagnostic yield of EGD in children: a retrospective singlecenter study of 1000 cases. Gastrointest Endosc. 2013;78(1):47-54.e1.

6. Wang S, Younus O, Rawat D, Naik S, Giles E, Meadows N, et al. Clinical Presentation and Outcomes of Diagnostic Endoscopy in Newly Presenting Children with Gastrointestinal Symptoms. J Pediatr Gastroenterol Nutr. 2018; 66(6):876-81.

7. Gómez Zuleta Martín Alonso. Ruiz Morales Óscar Fernando, Riveros Javier. Utilidad de la endoscopia digestiva alta diagnóstica en pacientes menores de 18 años. Rev Col Gastroenterol [Internet]. 2014 June [cited 2020 Apr 18]; 29(2): 112-116.

8. Lyons H, Zhang Y, Szpunar S, Dharmaraj R. Predictors of positive esophagogastroduodenoscopy outcomes in children and adolescents: a single center experience. BMC Res Notes. 2017;10(1):356.

9. Rawashdeh MO, Abu-Farsakh N, al-Jaberi TM. Paediatric upper gastrointestinal endoscopy in developing countries. Ann Trop Paediatr. 1996;16(4): $341-46$

10. Motamed F, Norouzi S, Najafi M, Khodadad A, Farahmand F, Mossahebi S,et al. Upper endoscopic findings in children with recurrent abdominal pain: high prevalence of hiatus hernia. Iran J Pediatr. 2012;22(3):309-13.

11. Alabd Alrazzak B, Husien T, Preston DL, Elitsur Y. Upper endoscopy in children: do symptoms predict positive findings? Clin Pediatr (Phila). 2014; 53(5):474-78.

12. Thomson M, Sharma S. Diagnostic Yield of Upper and Lower Gastrointestinal Endoscopies in Children in a Tertiary Centre. J Pediatr Gastroenterol Nutr. 2017;64(6):903-6.

13. Dahshan A, Rabah R. Correlation of endoscopy and histology in the gastroesophageal mucosa in children: are routine biopsies justified? J Clin Gastroenterol. 2000;31(3):213-16.

14. Teriaky A, AlNasser A, McLean C, Gregor J, Yan B. The Utility of Endoscopic Biopsies in Patients with Normal Upper Endoscopy. Can J Gastroenterol Hepatol. 2016; 2016:3026563.

15. Miele E, Giannetti E, Martinelli M, Tramontano A, Greco L, Staiano A. Impact of the Rome II paediatric criteria on the appropriateness of the upper and lower gastrointestinal endoscopy in children. Aliment Pharmacol Ther. 2010; 32(4):582-90.

\section{Publisher's Note}

Springer Nature remains neutral with regard to jurisdictional claims in published maps and institutional affiliations.

Ready to submit your research? Choose BMC and benefit from:

- fast, convenient online submission

- thorough peer review by experienced researchers in your field

- rapid publication on acceptance

- support for research data, including large and complex data types

- gold Open Access which fosters wider collaboration and increased citations

- maximum visibility for your research: over $100 \mathrm{M}$ website views per year

At $\mathrm{BMC}$, research is always in progress.

Learn more biomedcentral.com/submissions 